\title{
Characterization and influence of production factors on growing and finishing pig farms in Brazilian cooperatives
}

\author{
Caio Abércio da Silva ${ }^{1}$, Piero da Silva Agostini ${ }^{2}$, Cleandro Pazinato Dias ${ }^{3}$, Marco Aurélio \\ Callegari ${ }^{3}$, Rita de Kássia Silva dos Santos ${ }^{3}$, Aliny Kétilim Novais ${ }^{3}$, Carlos Rodolfo Pierozan ${ }^{3^{*}}$, \\ Josep Gasa Gasó ${ }^{2}$
}

\footnotetext{
${ }^{1}$ Universidade Estadual de Londrina, Centro de Ciências Agrárias, Departamento de Zootecnia, Londrina, PR, Brazil.

${ }^{2}$ Universitat Autònoma de Barcelona, Departament de Ciència Animal i dels Aliments, Bellaterra, Spain.

${ }^{3}$ Universidade Estadual de Londrina, Programa de Pós-graduação em Ciência Animal, Londrina, PR, Brazil.
}

\begin{abstract}
The objective of this study was to identify and quantify, through mathematical models, the main factors of production in growing and finishing pig units linked to three Brazilian cooperatives located in Western Region of Paraná State that influence the parameters of daily feed intake and feed conversion ratio. The records of 216 growing and finishing farms from 2010 to 2013, representing 1,533 batches, and totaling approximately 1,025,000 pigs, were evaluated. Thirty production factors related to the management, health, installations and equipment, nutrition, genetics, and environment were considered. The number of pigs per pen, the feeder model, the origin and sex of the animals, and the initial and final body weights were the factors included in the final models for both dependent variables (daily feed intake and feed conversion ratio) and had a significant impact on these ratios. Approximately, 41 and 55\% of the total variance found for daily feed intake and feed conversion ratio, respectively, were explained by the variables included in the final models. Mathematical models could serve as important tools to aid the decision-making in pig production systems.
\end{abstract}

Key Words: facilities, fattening, intake, production indexes, regression

\section{Introduction}

In recent decades, in many countries, the pig industry has become organized predominantly under cooperative or integrated companies with great herds and their producers focused to work with specific phases (or exclusively on farrow-to-wean or on growing-to-fattening) (Harris and Alexander, 1999; Maes et al., 2004; Krabbe et al., 2013).

In Brazil, more than $80 \%$ of the pig farmers are involved in specialized growing and finishing (GF) units that are linked to cooperatives or private companies (Daga et al., 2008). These units show important technological and efficiency differences related with the farm sizes, as well as regional differences. Thus, in the South and Southeast, the capacity is inferior (between $500-2,000$ pigs) than in the West Central region (more than 4,000 pigs).

Received: July 15, 2016

Accepted: November 29, 2016

*Corresponding author: carlospierozan@hotmail.com

http://dx.doi.org/10.1590/S1806-92902017000300012

How to cite: Silva, C. A.; Agostini, P. S.; Dias, C. P.; Callegari, M. A.; Santos, R. K. S.; Novais, A. K.; Pierozan, C. R. and Gasa Gasó, J. 2017. Characterization and influence of production factors on growing and finishing pig farms in Brazilian cooperatives. Revista Brasileira de Zootecnia 46(3):264-272.

Copyright (C) 2017 Sociedade Brasileira de Zootecnia. This is an Open Access article distributed under the terms of the Creative Commons Attribution License (http://creativecommons.org/licenses/by/4.0/), which permits unrestricted use, distribution, and reproduction in any medium, provided the original work is properly cited.
Although the growing and finishing phases are complex and their efficiency are subject to many production factors or variables, the movement of many animals and feed generates great concern with the cost. Despite the importance of GF phases, scientific studies, evaluating the effective production of GF units, commonly relate productive indexes to a unique productive factor (Losinger, 1998; Cline and Richert, 2001; Quiles and Hevia, 2008). The consideration of the various factors and their interactions over the specific parameters, especially genetics, facility model (Latorre et al., 2004; Gispert et al., 2007), nutrition (Niemi et al., 2010), health status (Martinez et al., 2009), and the management conditions (Street and Gonyou, 2008), is limited in these studies.

The evaluation of the effects of production factors on a particular performance parameter may be obtained through mathematical modelling. This tool aims to present a simplified way to describe real effects or to identify phenomena, from a mathematical point of view, using prediction and/or an explanation of a factor of interest (Mata, 2000). Mathematical models have allowed researchers in agricultural systems to develop concepts, methods, and tools to understand and direct the activity as a whole (Gibon et al., 1999), thereby assisting in decision-making.

The objective of this study, therefore, was to identify and quantify the various factors that affect the production of 
the pigs in growing and fattening phases, in a large region of pig production of Brazil, based on the daily feed intake and feed conversion ratio parameters, through mixed linear regression models.

\section{Material and Methods}

This study used a database that did not require approval by Ethical Committee on Animal Use, because no animal was used.

The production records of 216 commercial GF pig farms linked to three cooperatives located in the Western Region of Paraná State, Brazil, were evaluated (with 51, 90, and 75 farms for each cooperative related). The production data corresponded to the batches housed between 2010 and 2013, totaling 1,533 batches (with 358, 639, and 536 batches, respectively) and comprising approximately $1,025,000$ pigs. All batches were managed as all-in-all-out system.

The work model was based on the studies conducted by Agostini et al. (2013a,b), in which each batch of GF animals was considered an experimental unit. The production records were obtained through a standard questionnaire concerning production conditions, such as origin of animal, sex segregation, all-in-all-out system or continuous flux, feature hand labor, feeder, drinker, ventilation, and others. The variables (a total of 30) were understood as issues related to the main factors of production or livestock importance; these were based on the study developed by Agostini et al. (2013b) and by suggestions made by the professionals of the cooperatives involved.

The variables were divided into two sets: "independent" and "dependent". The independent variables were evaluated as continuous variables (e.g. initial body weight, final body weight, and length of growing and finishing phases) and as categorical variables (genetic lineages, type of feeder, ventilation system, etc.). The initial body weight indicates the live weight in kilograms when the pigs came into the GF unit and the final body weight refers to the live weight of pigs recorded at slaughterhouse. Length of growing and finishing phases is the period in days that the animals remained in the GF unit.

Within the dependent variables, daily feed intake (DFI) and feed conversion ratio (FCR) were considered continuous variables. The DFI was calculated from the amount of feed offered to the batch during the GF period, minus the amount of feed remaining in the silos when these animals were sent for slaughter; the difference was divided by the total number of animals in the batch and then divided by the average number of days that the animals remained in the GF unit. The FCR was calculated by dividing the total feed offered to batches by the difference between the initial body weight and the final body weight of animals in GF unit.

In addition to the categorical independent variables (also used in designs of DFI and FCR), continuous independent variables initial and final body weight and length of growing and finishing phases were used in the FCR model, whereas for the DFI model, just the first two variables were used, because the model was calculated considering the value of length of growing and finishing phases.

Statistical analyses were performed using SAS software (Statistical Analysis System, version 9.2). For statistical analysis, two phases were defined: exploratory analysis and model development.

In the exploratory analysis phase, a frequency study of the categorical variables was conducted using the FREQ procedure of SAS (occurrence percentages in Table 1). Measures of central tendency (mean and median) and dispersion (standard deviation, quartiles, and amplitude) for the continuous variables were computed using the MEANS procedure of SAS (Table 2). The distributions of continuous variables were evaluated using the UNIVARIATE procedure. In all these analyses, the batch was considered the experimental unit, defined as a single group of piglets that came from the nursery phase and were held in a GF unit until slaughter.

Mixed linear regression models were fit using the MIXED procedure, using the variables that were in the first phase coded as predictors. The effects: "cooperative", "farm aligned cooperative", and "batch aligned to the farm and cooperative" were considered as random factors and the variance was estimated using the restricted maximum likelihood method. The comparison of goodness of fit of the final models was based on the proportion of variance explained by the different models, using the coefficient of determination $\left(\mathrm{R}^{2}\right)$ as a parameter.

At the second phase, a single regression model was initially used, in which each variable was included as a fixed effect for each single dependent variable. The independent variables with $\mathrm{P} \leq 0.20$ were selected for use in the multivariate analysis.

Pearson's and Spearman's correlations were performed among independent variables to avoid multicollinearity between continuous variables and confounding problems between categorical variables. When two variables had high correlation coefficients (absolute value $\geq 0.60$ ), only one was used in the multivariate analysis; the choice between them was made by comparing the P-values in the univariate analysis and additionally evaluating 
their biological relevance with respect to the dependent variable. Subsequently, all independent variables selected in the univariate analysis were subjected to the procedure "stepwise", in which all factors with $\mathrm{P}<0.05$ were kept in the final multivariate model. Tests for the evaluation of fixed effects were based on an F-test with the WelchSatterthwaite approximation for the number of degrees of freedom in the denominator. Significant interactions $(\mathrm{P}<0.05)$ between the variables in the multivariate model were tested and included.

After the establishment of the models for each dependent variable, the residuals were plotted against the predicted values to check the homogeneity of variances and the presence of outliers. All the factors with $\mathrm{P}<0.05$ in the final models for each of the two dependent variables (DFI and FCR) were considered statistically significant.

\section{Results}

According the categorical variables (Table 1), a tendency for the presence of larger farms can be observed, so a greater number of the animals are placed in these farms and the majority of the farms were built in masonry and covered with clay tiles.

Regarding to the size of the pens, a higher percentage of farms had pens with a capacity for fewer than 20 animals and most were equipped with features such as composter (98.4\%) and trees around the barns (68.2\%).

Regarding the feeders, conical semiautomatic (74.8\%) feeders were prevalent. Additionally, the farms had typical pens with shallow pools to facilitate the management of waste.

The employment of familiar laborers was predominant (75.4\%) and the main management methods involved were the immunocastration and ractopamine (99.5\%), use of different feeds during the GF phases $(76.8 \%$ of the farms adopt five or more types of feed), use of pelleted feed (99.6\%), and sex segregation in the pens (76.7\%). Most farms received piglets from specialized piglet production units $(71.0 \%)$.

The daily feed intake per animal per batch was $2.14 \pm 0.10$ $\mathrm{kg}$ (ranging from 1.82 to $2.50 \mathrm{~kg}$ ) (Table 2). Multivariate regression analysis indicated that feed intake was influenced by the number of animals per pen $(\mathrm{P}<0.001)$, feeder model

Table 1 - Descriptive values of independent categorical variables

\begin{tabular}{|c|c|}
\hline Variable & Percentage $(\%)$ of batches in each category \\
\hline Semester of placement & Summer/autumn (49.58); winter/spring (50.42) \\
\hline Number of animals placed & $<500(13.96) ;>500(86.04)$ \\
\hline Number of barns & One (54.21); two or more (55.79) \\
\hline Stall age & $<5$ years $(38.21) ;>5$ years $(61.79)$ \\
\hline Repair of facilities & Yes (19.63); no (80.37) \\
\hline Number of pigs per pen & $<20(55.64) ;>20(44.36)$ \\
\hline Materials used to build the barn & Masonry (62.82); wood and mixed (37.18) \\
\hline Feeder model & Conical automatic (74.82); others (25.18) \\
\hline Drinker model & Nipple (89.63); water cup (10.37) \\
\hline Water source & Untreated water (32.68); treated water (67.32) \\
\hline Roof material & Clay (92.76); asbestos (2.15); zinc (5.09) \\
\hline Material used to separate the pens & Masonry (18.69); wood or mixed (81.31) \\
\hline Pens with shallow pools & Yes $(83.95)$; no $(16.05)$ \\
\hline Ventilation fans & Yes (5.87); no (94.13) \\
\hline Exhaust fans & No $(100)$ \\
\hline Humidifiers/nebulizers & Yes (32.22); no (67.78) \\
\hline Composters & Yes (98.43); no (1.57) \\
\hline Trees around the facilities & Yes (68.23); no (31.77) \\
\hline Barn position relative to the sun & Diagonal (22.31); contrary (26.22); parallel (51.47) \\
\hline Number of feed used in GF phases & $<4(23.25) ; 5$ or $>(76.75)$ \\
\hline Different feeds according to sex & No $(100)$ \\
\hline Feed form & Pelleted (99.61); mixed (0.39) \\
\hline Shock with antibiotics & Yes $(100)$ \\
\hline Programs used & Ractopamine (0.52); Ractopamine/immunocastration (99.48) \\
\hline Labor force & Familiar (75.47); non-familiar (24.53) \\
\hline Number of genetic lineages employed & $<4(65.04), 4$ or $>(34.96)$ \\
\hline Breeds used & Large White/Landrace/Pietrain (100) \\
\hline Sexed batches & Yes (58.32), No (41.68) \\
\hline Sex segregation in pens & Yes (76.65), No (23.35) \\
\hline Origin & SPU (70.97); farrowing-to-finish units (29.03) \\
\hline Sex & Barrows (26.81); females (23.81); mixed (49.38) \\
\hline
\end{tabular}

GF - growing and finishing; SPU - specialized piglet production units. 
$(\mathrm{P}<0.001)$, animal origin $(\mathrm{P}<0.05)$, sex $(\mathrm{P}<0.001)$, initial $(\mathrm{P}<0.001)$, and final body weight $(\mathrm{P}<0.001)$ (Table 3$)$.

Regarding the number of animals per pen, batches containing fewer than 20 animals had lower DFI $(0.035 \mathrm{~kg})$ compared with batches with more than 20 animals. Conical semiautomatic feeders increased the DFI $(0.026 \mathrm{~kg})$ compared with other models (with the dump feeding model as the most common after the semiautomatic model). The animals from specialized piglet production units showed greater DFI $(0.013 \mathrm{~kg})$ compared with batches of animals from farrow-to-finish farms. Furthermore, the separation of animals by sex showed a reduction in the DFI for batches of barrows $(0.012 \mathrm{~kg})$ and females $(0.041 \mathrm{~kg})$, compared with batches of mixed animals.

The variable initial body weight presented a positive relationship with the feed intake. For each kilogram of initial body weight, there was an increase of $0.007 \mathrm{~kg} / \mathrm{day}$ in feed intake. The variables included in the final model of DFI (Table 3) accounted for approximately $41 \%$ of the total variance found (Table 4). The proportions of variability explained between the model without any predictor (null model) and the final model with the selected variables included (full model) between companies, between farms related to a company, and between the batches related to a farm and company were $26.2,52.5$, and $40.3 \%$, respectively.

The average FCR was $2.45 \pm 0.12$ (ranging from 2.13 to 2.86) (Table 2) and was influenced by the following factors: number of animals per pen $(\mathrm{P}<0.001)$, materials used to build the barn $(\mathrm{P}<0.05)$, type of feeder $(\mathrm{P}<0.01)$, animal origin $(\mathrm{P}<0.05)$, sex $(\mathrm{P}<0.001)$, initial body weight $(P<0.001)$, final body weight $(P<0.001)$, and length of the GF phases $(\mathrm{P}<0.001)$ (Table 5).

Table 2 - Measures of central tendency and dispersion for the continuous variables

\begin{tabular}{|c|c|c|c|c|c|c|c|c|}
\hline Variable & Number of batches & Mean & SD & Low & Lower quartile & Median & Upper quartile & Upper \\
\hline Initial body weight $(\mathrm{kg})$ & 1,533 & 22.65 & 1.42 & 15.61 & 21.87 & 22.78 & 23.49 & 27.65 \\
\hline Number of pigs per batch & 1,533 & 669 & 340 & 102 & 500 & 600 & 830 & 2,393 \\
\hline Final body weight $(\mathrm{kg})$ & 1,533 & 116.75 & 5.01 & 98.81 & 113.56 & 116.67 & 119.97 & 137.81 \\
\hline Number of finished pigs & 1,533 & 653 & 329 & 98 & 492 & 583 & 806 & 2,316 \\
\hline Daily feed intake $(\mathrm{kg})$ & 1,532 & 2.14 & 0.10 & 1.82 & 2.07 & 2.14 & 2.21 & 2.50 \\
\hline Daily weight gain $(\mathrm{kg})$ & 1,533 & 0.88 & 0.05 & 0.72 & 0.84 & 0.87 & 0.91 & 1.03 \\
\hline
\end{tabular}

GF - growing and finishing; SD - standard deviation.

Table 3 - Mathematical model to estimates of the effects of the factors of production on daily feed intake

\begin{tabular}{|c|c|c|c|c|c|c|}
\hline \multirow{2}{*}{ Variable } & \multirow{2}{*}{ Category } & \multirow{2}{*}{ Estimate $^{1}$} & \multirow{2}{*}{ SE } & \multicolumn{3}{|c|}{$95 \%$ confidence interval } \\
\hline & & & & Low & Upper & P-value \\
\hline Intercept & & 0.763 & 0.059 & 0.634 & 0.893 & $<0.001$ \\
\hline Number of pigs per pen & $>20$ & 0 & - & - & - & - \\
\hline \multirow[t]{2}{*}{ Feeders } & Others (linear dump) & -0.026 & 0.007 & -0.041 & -0.012 & 0.004 \\
\hline & Conical semiautomatic & 0 & - & - & - & - \\
\hline Water source & Treated & 0 & - & - & - & - \\
\hline \multirow[t]{2}{*}{ Pens with shallow pools } & Yes & 0.018 & 0.009 & -0.001 & 0.036 & 0.060 \\
\hline & No & 0 & - & - & - & - \\
\hline \multirow[t]{2}{*}{ Origin/animal } & SPU & 0.013 & 0.006 & 0.002 & 0.025 & 0.019 \\
\hline & Farrowing-to-finish & 0 & - & - & - & - \\
\hline Number of genetic lineages & 4 or $>$ & 0 & - & - & - & - \\
\hline Initial body weight (kg) & & 0.007 & 0.001 & 0.005 & 0.010 & $<0.001$ \\
\hline Final body weight (kg) & & 0.010 & 0.000 & 0.009 & 0.011 & $<0.001$ \\
\hline
\end{tabular}

SPU - specialized piglet production units; SE - standard error.

${ }^{1}$ Values are in $\mathrm{kg}$ per pig. 
Notably, the FCR was improved by approximately 4 points ( $4 \mathrm{~kg}$ of feed $/ 100 \mathrm{~kg}$ pig live weight), when the number of animals housed per pen was less than 20 , compared with batches coming from pens with more than 20 animals. Animals housed in barns built in masonry showed 2.5 points better FCR than those housed in barns of wood and/or mixed material (masonry and wood). Conical semiautomatic feeders resulted in worsening of the FCR (2.6 points), compared with other feeders. Specialized piglet production unit animals showed an improvement of the FCR (1.3 point) relative to animals coming from farrow-to-finish farms. Regarding the sex of the animals, there was an improvement of the FCR for the batches of barrows (2.1 points) and females (4.9 points) relative to batches of animals of both sexes.

Regarding the variable initial body weight, when its value was higher, the FCR worsened, with an absolute increase of 3.1 points in FCR observed for each kilogram of initial body weight. Additionally, heavier weights at slaughter indicate better FCR and for each kilogram of final weight, the index was 1.2 point greater. This situation is in contrast to the length of GF phases, in which there was a worsening of 1.5 point for each extra day of housing.

The variables included in the final model to the FCR (Table 5) accounted for $55 \%$ of the total variance found (Table 6). The proportions of variability explained between the model without any predictor (null model) and the final model with the selected variables included (full model) between companies, between farms related to a company, and between the batches related to a farm and company were $94.7,40.3$, and $53.6 \%$, respectively.

\section{Discussion}

One aspect observed in this study concerns the variability explained between cooperatives. Approximately 26.2 and $94.7 \%$ of the variability observed between cooperatives in the null model for DFI and FCR, respectively, was explained

Table 4 - Variance among cooperatives, farms within a cooperative, and batches within a farm and cooperative for model without predictors (null model) and multivariate model (full model) for daily feed intake

\begin{tabular}{|c|c|c|c|c|c|}
\hline \multirow{2}{*}{ Effect } & \multicolumn{2}{|c|}{ Null model } & \multicolumn{2}{|c|}{ Full model } & \multirow{2}{*}{$\begin{array}{c}\text { Variability explained } \\
\% \\
\end{array}$} \\
\hline & Variance & $\%$ & Variance & $\%$ & \\
\hline Cooperatives & 0.00133 & 12.2 & 0.00098 & 15.3 & 26.2 \\
\hline Farms (cooperative) & 0.00228 & 20.9 & 0.00109 & 16.9 & 52.5 \\
\hline Batches (cooperative $\times$ farm) & 0.00729 & 66.9 & 0.00436 & 67.8 & 40.3 \\
\hline Total & 0.01091 & 100 & 0.00643 & 100 & 41.1 \\
\hline
\end{tabular}

Table 5 - Mathematical model to estimates of the effects of the factors of production on feed conversion ratio

\begin{tabular}{|c|c|c|c|c|c|c|}
\hline \multirow{2}{*}{ Variable } & \multirow{2}{*}{ Category } & \multirow{2}{*}{ Estimate $^{1}$} & \multirow{2}{*}{ SE } & \multicolumn{3}{|c|}{$95 \%$ confidence interval } \\
\hline & & & & Low & Upper & P-value \\
\hline Intercept & & 1.589 & 0.075 & 1.440 & 1.736 & $<0.001$ \\
\hline Number of pigs per pen & $\begin{array}{l}<20 \\
>20\end{array}$ & $\begin{array}{c}-0.041 \\
0\end{array}$ & $\begin{array}{c}0.008 \\
-\end{array}$ & $\begin{array}{c}-0.057 \\
-\end{array}$ & $\begin{array}{c}-0.025 \\
-\end{array}$ & $\begin{array}{c}<0.001 \\
-\end{array}$ \\
\hline Materials used to build the barn & $\begin{array}{c}\text { Masonry } \\
\text { Others (wood and mixed) }\end{array}$ & $\begin{array}{c}-0.025 \\
0\end{array}$ & $\begin{array}{c}0.011 \\
-\end{array}$ & $\begin{array}{c}-0.047 \\
-\end{array}$ & $\begin{array}{c}-0.004 \\
-\end{array}$ & $\begin{array}{c}0.022 \\
-\end{array}$ \\
\hline Feeders & $\begin{array}{l}\text { Others (linear dump) } \\
\text { Conical semiautomatic }\end{array}$ & $\begin{array}{c}-0.026 \\
0\end{array}$ & $\begin{array}{c}0.008 \\
-\end{array}$ & $\begin{array}{c}-0.042 \\
-\end{array}$ & $\begin{array}{l}-0.010 \\
-\end{array}$ & $\begin{array}{c}0.001 \\
-\end{array}$ \\
\hline Origin/animal & $\begin{array}{l}\text { SPU } \\
\text { Farrowing-to-finish }\end{array}$ & $\begin{array}{c}-0.013 \\
0\end{array}$ & $\begin{array}{c}0.007 \\
-\end{array}$ & $\begin{array}{c}-0.026 \\
-\end{array}$ & $\begin{array}{c}0.000 \\
-\end{array}$ & $\begin{array}{c}0.049 \\
-\end{array}$ \\
\hline Sex & $\begin{array}{c}\text { Barrows } \\
\text { Females } \\
\text { Mixed }\end{array}$ & $\begin{array}{c}-0.021 \\
-0.049 \\
0\end{array}$ & $\begin{array}{c}0.006 \\
0.006 \\
-\end{array}$ & $\begin{array}{c}-0.032 \\
-0.060 \\
-\end{array}$ & $\begin{array}{c}-0.010 \\
-0.038 \\
-\end{array}$ & $\begin{array}{l}<0.001 \\
<0.001 \\
-\end{array}$ \\
\hline Number of feed used & $\begin{array}{c}4 \text { or }< \\
5\end{array}$ & $\begin{array}{c}0.052 \\
0\end{array}$ & $\begin{array}{c}0.013 \\
-\end{array}$ & $\begin{array}{c}-0.092 \\
-\end{array}$ & $\begin{array}{c}0.196 \\
-\end{array}$ & $\begin{array}{c}0.147 \\
-\end{array}$ \\
\hline Initial body weight $(\mathrm{kg})$ & & 0.031 & 0.002 & 0.028 & 0.034 & $<0.001$ \\
\hline Final body weight $(\mathrm{kg})$ & & -0.012 & 0.0005 & -0.013 & -0.011 & $<0.001$ \\
\hline LGF (days) & & 0.015 & 0.001 & 0.014 & 0.017 & $<0.001$ \\
\hline
\end{tabular}

SPU - specialized piglet production units; LGF - length of growing and finishing period; SE - standard error.

${ }^{1}$ Values are in $\mathrm{kg}$ of feed per $\mathrm{kg}$ of pig 
Table 6 - Variance among cooperatives, farms within a cooperative, and batches within a farm and cooperative for model without predictors (null model) and multivariate model (full model) for feed conversion ratio

\begin{tabular}{|c|c|c|c|c|c|}
\hline \multirow{2}{*}{ Effect } & \multicolumn{2}{|c|}{ Null model } & \multicolumn{2}{|c|}{ Full model } & \multirow{2}{*}{$\begin{array}{c}\text { Variability explained } \\
\% \\
\end{array}$} \\
\hline & Variance & $\%$ & Variance & $\%$ & \\
\hline Cooperatives & 0.00119 & 8.1 & 0.00006 & 1.0 & 94.7 \\
\hline Farms (cooperative) & 0.00212 & 14.4 & 0.00127 & 19.0 & 40.3 \\
\hline Batches (cooperative $\times$ farm) & 0.01145 & 77.5 & 0.00531 & 80.0 & 53.6 \\
\hline Total & 0.01477 & 100 & 0.00664 & 100 & 55.0 \\
\hline
\end{tabular}

by the inclusion of the variables selected in the final models (full model). This big difference observed between DFI and FCR might be due to the inclusion of the variable "materials used to build the barn" to the model for FCR, since most farms that were built with masonry seemed to have a better FCR, regardless of the cooperative.

After the inclusion of the variables in the final models, $59 \%$ of the variability for DFI and $45 \%$ for FCR remained unexplained, especially concerning the variance between batches within a farm, which corresponded to $40 \%$ for DFI, being different from 59\%, and $36 \%$ for FCR, also distinct from $45 \%$ found. Similar findings were also found by Pierozan et al. (2016) for DFI and FCR.

The factors included in the final models for the parameters DFI and FCR exhibit influence on these dependent variables. The total variance of these variables is explained in $41 \%$ and $55 \%$ for the DFI and FCR, respectively, representing different values from those obtained by Oliveira et al. (2009), who found $81 \%$ of total variance for feed intake, and by Agostini et al. (2013a), who observed $62 \%$ of total variance for feed intake and $25 \%$ for feed conversion. One possible explanation for the differences in these results is the variability in the factors discussed, including differences in climate, production systems, and organizational structure of the companies in which these studies were conducted.

The semester of placement (related with the seasons of the year) is a factor that did not influence the DFI and FCR. Brazil has poorly defined seasons, with average temperatures between $15-18{ }^{\circ} \mathrm{C}$ for the coldest quarter (June, July, and August) and $26-29{ }^{\circ} \mathrm{C}$ in the warmest quarter (December, January, and February) in the region where the farms belonging to companies of this study are located (Caviglione, 2000). Therefore, this condition was probably the reason for the absence of a significant effect of season on the parameters, which is in contrast to the results obtained by Agostini et al. (2013a,b) for European farms.

Batches that placed less than 20 animals per pen presented lower DFI and better FCR. Averós et al. (2010b) observed in many studies an unclear relation between the group size and the available space per pig, resulting in difficulties to interpret and draw conclusions about these factors. Therefore, Vermeer et al. (2014) studied the effect of different pen (and group) sizes associated with the available space per animal on welfare and on performance of GF pigs and found that animals maintained in larger groups grow more slowly than animals housed in smaller groups. Street and Gonyou (2008) found that pigs in the GF phases that were housed in small groups (18 animals) gained $3 \%$ more weight and had a $6 \%$ better feed efficiency than those housed in large groups (108 animals). The group size has a relationship with the behavior of pigs. Pigs in large groups spend less time sitting and lying and have more time dedicated to exploratory and social behaviors, being admitted in the literature that, generally, pigs demonstrate more activity when the group size is increased (Averós et al., 2010a). Thus, the dietary energy can be used to attempt these behaviors, which may explain the worse FCR in large groups, although, according to Averós et al. (2010a), the effect of size group on the performance depends strongly on the age of the animal.

On the other hand, there are still many contradictions about the best group size. Pigs seem to become less aggressive in large groups, probably due to the high number of potential competitors (Samarakone and Gonyou, 2009). However, Vermeer et al. (2014) concluded that pigs in large groups have more tail-biting injuries. Then, it is possible to admit that there is no consensus on the ideal group size for GF animals yet (Dias et al., 2014). Pigs that were recently placed in large batches in GF phases had a penalization of their performance. Li and Johnston (2009) found that pigs in unfamiliar groups derived from large groups show lower DFI and daily weight gain during the first six weeks of the growing phase, and they are more aggressive and present more injuries in the early days of the grouping.

Regarding the materials used to build the barn, worse results were observed to the FCR when wood was used. Wood is a porous material that exhibits poor cleaning and disinfection efficiency, which may lead to adverse effects on health and, therefore, to the performance of animals. 
Additionally, the use of wood is often associated with older farms, which, in addition, commonly present a worse environmental sanity and have poorer and more inefficient facilities than modern farms.

About the feeders, the conical semiautomatic models, while more practical, can increase the DFI and result in worse efficiency in FCR than other models, of which the dump feeder was the most prevalent model. The adjustment in the feeder to regulate the provision of feed has influence over the food waste, which may worsen the feed efficiency of the pigs (Euken, 2012). According to Heck (2009), the high cost to purchase the new feeders and the need for modification of facilities are factors that make it difficult to carry out experiments with different models of feeders.

Studies by Bergstrom et al. (2012) and Agostini et al. (2013a) showed that pigs in the GF phases with access to feeders coupled with drinkers have better growth rates. Similarly, Yang et al. (2001) observed that animals with access to feeders that incorporated water have better intestinal morphology, with increased villus height, suggesting that the moistened feed promotes better digestion and absorption of nutrients.

The adjustment of the feeder plays an important role on feed conversion, improving it, because even a very small adjustment can result in a little increase in the daily weight gain. Goodband et al. (2008) compared three different settings of five commercial automatic feeder models for dry feed, in which the first setting corresponded to an $80 \%$ provision of feed to fill the depth of the feeder; the second, 55\%; and the third, $15 \%$. They observed that at $80 \%$ setting, the same weight gain was achieved as when the feeder was adjusted to $55 \%$, but with increased cost and more wasted feed. Under the $15 \%$ setting, the daily weight gain was restricted and feed efficiency was worst. The size and the design of the feeder can contribute significantly to feed waste and, consequently, result in worse rates of feed conversion. For example, Gonyou and Lou (2000) found changes in eating habits of the pigs (eating with head up, fighting at the feeder, and getting into the feeder) related with the feeder characteristics, leading the animals to waste more food.

Regarding the animal origin, this factor can represent an important challenge in GF phases with great impact over the performance. The animals that came from specialized piglet production unit showed higher DFI and better FCR. This result was probably due to the better health status of the piglets. Piglets that came from different farrow-tofinish farms or nurseries and were destined to be placed later in GF units, commonly present greater health problems, with negative consequences on performance
(Agostini et al., 2013a). Many origins favor the presence of different pathogens and affect the immunological status of animals. Pig batches from a single origin presented a better feed conversion than batches from more than one origin (Agostini et al., 2015).

Although the majority of the cooperatives and private companies adopts the all-in-all-out system, sometimes it is necessary to acquire animals from other farms to complete the batch, which can cause new health problems and damage to the batch performance (Oliveira et al., 2007; Amaral and Mores, 2008). This procedure was probably the reason of the differences in performance (DFI and FCR) observed in this work.

Regarding to sex factor, there was a reduction in DFI and an improvement in FCR in castrated male batches and female batches, compared with mixed batches. These results are consistent with those obtained by Morales et al. (2010), who compared groups of intact males, castrated males, and females during the GF phases (74-172 days of age). They found that castrated males showed a worse FCR, 10.6\% and $7.0 \%$ higher than intact males and females, respectively, confirming that castrated males develop greater feed intake; however, they have worse feed efficiency and less deposition of lean meat (Brustolini and Fontes, 2014). Although the females present better FCR compared with castrated males, recent studies have shown a DFI deficit for them, which requires an increase around six days to reach the same slaughter weight of males (Sundrum et al., 2011; Brustolini and Fontes, 2014).

The effects of the identified factors over the DFI and FCR may guide changes, favoring the improvement of these parameters. However, the investments required, their costs, and the dynamics of the process should be considered, which indicate a need for frequent reviews to update how these factors affect the production rates.

\section{Conclusions}

The mathematical models obtained show the quantitative effects of some production factors over the feed intake (number of pigs per pen, feeders, pens with shallow pools, origin, and sex of animals) and over the feed conversion (number of pigs per pen, materials used to build the barn, feeders, origin, and sex of animals). The changes of these factors aiming to optimize the production rates shall be analyzed carefully because they may incur in more costs that cannot be recovered easily. The validation and the update of the factors should be done regularly to ensure the accuracy of the effects on the performance parameters. 


\section{Acknowledgments}

Firstly, the authors wish to thank the participating cooperatives, which trusted us with the data from their farms so that this study could be developed. The authors also thank the public research project funded by the Spanish Ministry of Education, Culture and Sport (AGL 2011-29960), with which this study was developed.

\section{References}

Agostini, P. S.; Fahey, A. G.; Manzanilla, E. G.; O’Doherty, J. V.; de Blas, C. and Gasa, J. 2013a. Management factors affecting mortality, feed intake and feed conversion ratio of grow-finishing pigs. Animal 8:1312-1318.

Agostini, P. S.; Gasa, J.; Manzanilla, E. G.; Silva, C. A. and Blas, C. 2013b. Descriptive study of production factors affecting performance traits in growing-finishing pigs in Spain. Spanish Journal of Agricultural Research 11:371-381.

Agostini, P. S.; Manzanilla, E. G.; Blas, C.; Fahey, A. G.; Silva, C. A. and Gasa, J. 2015. Managing variability in decision making in swine growing-finishing units. Irish Veterinary Journal 68:20-33.

Amaral, A. L. and Mores, N. 2008. Planning of pig production in batches with empty period. Acta Scientiae Veterinariae 36:143-154.

Averós, X.; Brossard, L.; Dourmad, J. Y.; de Greef, K. H.; Edge, H. L.; Edwards, S. A. and Meunier-Salaün, M. C. 2010a. A meta-analysis of the combined effect of housing and environmental enrichment characteristics on the behaviour and performance of pigs. Applied Animal Behaviour Science 127:73-85.

Averós, X.; Brossard, L.; Dourmad, J. Y.; de Greef, K. H.; Edge, H. L.; Edwards, S. A. and Meunier-Salaün, M. C. 2010b. Quantitative assessment of the effects of space allowance, group size and floor characteristics on the lying behaviour of growing-finishing pigs. Animal 4:777-783.

Bergstrom, J. R.; Nelssen, J. L.; Tokach, M. D.; Dritz, S. S.; Goodband, R. D. and DeRouchey, J. M. 2012. Effects of two feeder designs and adjustment strategies on the growth performance and carcass characteristics of growing-finishing pigs. Journal of Animal Science 90:4555-4566.

Brustolini, A. P. L. and Fontes, D. O. 2014. Fatores que afetam a exigência nutricional de suínos na terminação. p.677-685. In: Produção de suínos: Teoria e prática. Associação Brasileira dos Criadores de Suínos, Brasília.

Caviglione, J. H.; Kiihl, L. R. B.; Caramori, P. H. and Oliveira, D. 2000. Cartas climáticas do Paraná. IAPAR, Londrina. Available at: $<\mathrm{http} / /$ www.iapar.br/modules/conteudo/conteudo.php? conteudo $=860>$. Accessed on: Apr. 8, 2016.

Cline, T. R. and Richert, B. T. 2001. Feeding growing-finishing pigs. p.717-724. In: Swine nutrition. Lewis, A. J. and Southern, L. L., eds. CRC Press, Boca Raton.

Daga, J.; Campos, A. T.; Feiden, A.; Klosowski, E. S. and Câmara, R. 2008. Análise da adequação ambiental e manejo dos dejetos de instalações para suinocultura em propriedades na região oeste do Paraná. Engenharia Agrícola 27:1-11.

Dias, C. P.; Silva, C. A. and Manteca, X. 2014. Bem-estar dos suínos. O Autor, Londrina.

Euken, R. M. 2012. Swine feed efficiency: impact of feeder designs and management. Iowa Pork Industry Center Fact Sheets. Iowa State University, Iowa.

Gibon, A.; Sibbald, A. R. and Thomas, C. 1999. Introduction: Improved sustainability in livestock systems, a challenge for animal production science. Livestock Production Science 61:107-110.
Gispert, M.; Font, I.; Furnols, M.; Gil, M.; Velarde, A.; Diestre, A.; Carrión, D.; Sosnicki, A. A. and Plastow, G. S. 2007. Relationships between carcass quality parameters and genetic types. Meat Science 77:397-404.

Gonyou, H. W. and Lou, Z. 2000. Effects of eating space and availability of water in feeders on productivity and eating behavior of grower/finisher pigs. Journal of Animal Science 78:865-870.

Goodband, B.; Tokach, M.; Dritz, S.; Derouchey, J. and Nelssen, J. 2008. Feeding and feeder management influences on feed efficiency. p.20-27. In: Proceedings of Allen D. Leman Swine Conference. Kansas State University, Minnesota.

Harris, L. and Alexander, T. J. 1999. Methods of disease control. p.1077-1110. In: Diseases of swine. 8th ed. Straw, B. E.; D'Allaire, S.; Mengling, W. L. and Taylor, D. J., eds. Iowa State University Press, Ames.

Heck, A. 2009. Fatores que influenciam o desenvolvimento dos leitões na recria e terminação. Acta Scientiae Veterinariae 37:211-218.

Krabbe, E. L.; Santos Filho, J. E.; Miele, M. and Martins, F. M. 2013. Cadeias produtivas de aves e suínos. p.9-32. In: Tópicos atuais na produção de suínos e aves. Gentilini, F. P. and Anciuti, M. A., eds. IFSul, Pelotas.

Latorre, M. A.; Lázaro, R.; Valencia, D. G.; Medel, P. and Mateos, G. G. 2004. The effects of gender and slaughter weight on the growth performance, carcass traits, and meat quality characteristics of heavy pigs. Journal of Animal Science 82:526-533.

Li, Y. Z. and Johnston, L. J. 2009. Behavior and performance of pigs previously housed in large groups. Journal of Animal Science $87: 1472-1478$

Losinger, W. C. 1998. Feed-conversion ratio of finisher pigs in the USA. Preventive Veterinary Medicine 36:287-305.

Maes, D.; Duchateau, L.; Larriestra, A. J.; Deen, J. and Morriso, R. B. 2004. Risk factors for mortality in grow-finishing pigs in Belgium. Journal of Veterinary Medicine Series B Infectious, Diseases and Veterinary Public Health 51:321-326.

Martinez, J.; Peris, B.; Gómez, E. A. and Corpa, J. M. 2009. The relationship between infectious and non-infectious herd factors with pneumonia at slaughter and productive parameters in fattening pigs. The Veterinary Journal 179:240-246.

Mata, D. V. 2000. Construcción y utilización de un modelo estocástico para la simulación de estrategias de manejo invernal en rebaños de vacas nodrizas. Thesis (D.Sc.). Universitat de Lleida, Lleida, Spain.

Morales, J.; Gispert, M.; Hortos, M.; Perez, J.; Suarez, P. and Piñeiro, C. 2010. Evaluation of production performance and carcass quality characteristics of boars immunised against gonadotropin-releasing hormone $(\mathrm{GnRH})$ compared with physically castrated male, entire male and female pigs. Spanish Journal of Agricultural Research 8:599-606.

Niemi, J. K.; Sévon-Aimonen, M. L.; Pietola, K. and Stalder, K. J. 2010. The value of precision feeding technologies for grow-finish swine. Livestock Science 129:13-23.

Oliveira, J.; Guitián, F. J. and Yus, E. 2007. Effect of introducing piglets from farrow-to-finish breeding farms into all-in all-out fattening batches in Spain on productive parameters and economic profit. Preventive Veterinary Medicine 80:243-256.

Oliveira, J.; Yus, E. and Guitián, F. J. 2009. Effects of management, environmental and temporal factors on mortality and feed consumption in integrated swine fattening farms. Livestock Science 123:221-229.

Pierozan, C. R.; Agostini, P. S.; Gasa, J.; Novais, A. K.; Dias, C. P.; Santos, R. K. S.; Pereira Junior, M.; Nagi, J. G.; Alves, J. B. and Silva, C. A. 2016. Factors affecting the daily feed intake and feed conversion ratio of pigs in grow-finishing units: the case of a company. Porcine Health Management 2:1-8. 
Quiles, A. and Hevia, M. L. 2008. Factores que influyen en el consumo de pienso en los cerdos. Producción Animal 248:6-19.

Samarakone, T. S. and Gonyou, H. W. 2009. Domestic pigs alter their social strategy in response to social group size. Applied Animal Behaviour Science 121:8-15.

Street, B. R. and Gonyou, H. W. 2008. Effects of housing finishing pigs in two group sizes and at two floor space allocations on production, health, behavior, and physiological variables. Journal of Animal Science 86:982-991.

Sundrum, A.; Aragon, A.; Schulze-Langenhorst, C.; Bütfering, L.; Henning, M. and Stalljohann, G. 2011. Effects of feeding strategies, genotypes, sex, and birth weight on carcass and meat quality traits under organic pig production conditions. NJAS - Wageningen Journal of Life Sciences 58:163-172.

Vermeer, H. M.; de Greef, K. H. and Houwers, H. W. J. 2014. Space allowance and pen size affect welfare indicators and performance of growing pigs under Comfort Class conditions. Livestock Science 159:79-86.

Yang, J. S.; Lee, J. H.; Ko, T. G.; Kim, T. B.; Chae, B. J.; Kim, Y. Y. and Han, I. K. 2001. Effects of wet feeding of processed diets on performance, morphological changes in the small intestine and nutrient digestibility in weaned pigs. Asian Australasian Journal of Animal Sciences 14:1308-1315. 